\title{
Quantification of plastic shrinkage cracking in mortars using digital image correlation
}

Bertelsen, I.M.G.; Kragh, C.; Cardinaud, G.; Ottosen, L.M.; Fischer, G.

Published in:

Cement and Concrete Research

Link to article, DOI:

10.1016/j.cemconres.2019.05.006

Publication date:

2019

Document Version

Peer reviewed version

Link back to DTU Orbit

Citation (APA):

Bertelsen, I. M. G., Kragh, C., Cardinaud, G., Ottosen, L. M., \& Fischer, G. (2019). Quantification of plastic shrinkage cracking in mortars using digital image correlation. Cement and Concrete Research, 123, [105761]. https://doi.org/10.1016/j.cemconres.2019.05.006

\section{General rights}

Copyright and moral rights for the publications made accessible in the public portal are retained by the authors and/or other copyright owners and it is a condition of accessing publications that users recognise and abide by the legal requirements associated with these rights.

- Users may download and print one copy of any publication from the public portal for the purpose of private study or research.

- You may not further distribute the material or use it for any profit-making activity or commercial gain

- You may freely distribute the URL identifying the publication in the public portal 
1 Quantification of plastic shrinkage cracking in mortars using digital image correlation

2 I. M. G. Bertelsen ${ }^{a}$, C. Kragh ${ }^{\mathrm{a}}$, G. Cardinaud ${ }^{\mathrm{a}, \mathrm{b}}$, L. M. Ottosen ${ }^{\mathrm{a}}$, G. Fischer ${ }^{\mathrm{a}}$,

3 a Department of Civil Engineering, Technical University of Denmark, Brovej 118, 2800 Kgs. Lyngby, Denmark

$4 \quad{ }^{\mathrm{b}}$ GeM, Ecole Centrale de Nantes, 1 Rue de la Noë, 44300 Nantes, France

$5 \quad *$ Corresponding author. E-mail: imgber@byg.dtu.dk

This study presents a digital image correlation (DIC) technique for the detection and quantification of plastic shrinkage cracking in thin restrained mortar overlays applied on concrete substrates. The non-contact 2D-DIC technique enables measurements of in-plane surface strain and displacement under continuous monitoring. A post-processing procedure to compute various crack parameters, such as crack location, width, length and area on the specimen surface is presented, which enables the crack patterns to be synthesized and digitally reproduced from DIC data. The formation of surface cracking is illustrated in histograms facilitating a quantitative analysis. The crack width measurements obtained by DIC data were verified using an optical microscope. The temperature evolution, evaporation rate and free shrinkage behaviour of unrestrained mortar specimens were also tested to increase the knowledge of the early-age behaviour. This method is intended for evaluation of various shrinkage mitigation strategies in cement-based mortars and other repair mortars.

Key words: Plastic shrinkage, Image Analysis, Crack detection, Cement-based materials, Digital image correlation

\section{Introduction}

Plastic shrinkage is the volumetric contraction of cement-based materials that occurs in the first few hours after casting when the concrete is still in a plastic stage. In restrained overlays, the material is not allowed to deform freely, so the contraction will generate tensile stresses that may result in surface cracking [1]. The restraint may be due to adhesion to an underlying concrete substrate, steel reinforcement, large aggregates, deviation in overlay geometry, adjacent formwork, or deformation gradients between layers in the material [1-4]. Most plastic shrinkage cracking is caused by the evaporation of mixing water and capillary pressure inside the pores of the cement. The loss of mixing water from 
substrate materials [5]. Specific environmental conditions, such as low relative humidity, elevated temperatures and exposure to high wind velocities, can enhance the water evaporation rate, and thereby the severity of plastic shrinkage cracking. Large plastic shrinkage deformations can result in severe crack formation on the surface of the material, which will affect its long-term durability, so it is essential to avoid the development of this type of cracking [1]. After setting, the cracks may propagate, allowing the ingress of aggressive agents and leading to the premature deterioration of the steel reinforcement.

The literature describes several methods for characterizing early-age shrinkage-induced cracking in cement-based materials. These include the method proposed in ASTM C1579 (2013) [6], where cracking is induced by triangular stress risers; the ring test method proposed in [7,8]; the linear dogbone-shaped specimens with restrained ends [9,10]; the plate-shaped specimens with edge-restraints proposed by Kraai [11]. These methods are effective for comparative testing of the cracking behaviour under laboratory conditions, but are not considered appropriate for simulation of realistic stress fields and crack patterns in the material [5]. Methods where a fresh overlay is cast on top of a restraining concrete substrate or rough surface have also been developed for bonded overlays and are considered to provide more realistic stress fields $[1,3,12-17]$. In these experiments, the fresh overlay may be simulating a repair mortar applied on a damaged concrete surface (substrate) to increase the structural capacity, to replace deteriorated concrete and/or to improve the durability by increasing the thickness of the concrete cover, thus protecting the steel reinforcement against corrosion. The method developed in this study addresses crack formation in these last-mentioned bonded overlaysubstrate methods with restraints provided at the interface.

\subsection{Quantification of crack patterns}

Quantification of shrinkage cracking in restrained cement-based overlays can be challenging due to the unknown location of the cracks being formed and the difficulties in instrumenting these cracks to quantify their formation and growth. The evaluation of plastic shrinkage cracking is often based on visual inspection of the cracked surface and subsequent determination of crack parameters such as the mean and maximum crack width and length and the total crack area based on manual measuring techniques. However, parameters such as time of crack formation, crack width development, spacing between cracks, crack depth, crack length and crack width distribution are also of importance for future durability [18], and are difficult to quantify with manual measuring techniques. Actual measuring techniques presented in the literature include manual crack measurements using optical microscopes or hand-held lenses [14,19,20] or more sophisticated image-based techniques. The first mentioned techniques are considered to be time consuming, 
difficult to apply while the experiment is running, and therefore not optimal for observing crack propagation at early age occurring over short periods of time. The quality of the crack measurements relies upon various operator-dependent factors such as experience and expertise, and is therefore prone to human error [21]. Moreover, these techniques often provide very limited information about the cracked area and it is especially challenging to quantify crack patterns such as those that often occur in evenly restrained materials. More advanced image analysis techniques, such as digital image processing (DIP) [21-27] and digital image correlation (DIC) [13,15,16,28-33], have recently been successfully applied for detection of shrinkage-induced cracking in cement-based structures. These are non-contact techniques and work by capturing high-resolution images of the cracked surface, which makes it possible to track the evolution in crack growth in a series of pictures taken almost directly after casting. These techniques do not rely on operator-dependent factors; their accuracy simply depends on the setup, e.g. the resolution of the images, constant light source, and quality of the investigated surface [34]. In the DIP method, it is possible to analyse crack patterns by modifying the contrast of the images and then analyse whether a pixel is "cracked" or "uncracked". The DIC technique also enables strain and displacement contour maps to be created with sub-pixel accuracy, and DIC is suitable in order to achieve a better understanding of the surface deformations and cracking behaviour [35].

\subsubsection{D-DIC principles}

The DIC technique is an optical method for tracking displacements in images based on changes in the grey scale intensity of an applied speckle pattern [36]. The method has been widely accepted as an effective tool for surface deformation measurements in the field of experimental solid mechanics [35,37]. A single fixed digital charge coupled device (CCD) camera, a constant light source, and a high-contrast surface pattern for the detection of displacements on the investigated surface are all that is needed for two-dimensional DIC, which is limited to in-plane deformations [38]. The technique has also gained attention in concrete-related research, but has mostly been used to evaluate deformations and fractures in already hardened cementitious materials in several types of test e.g. [13,38-41]. Mauroux et al. [13,42] studied the formation of drying shrinkage of coating mortars (both free and restrained specimens) and applied a 2D-DIC system for monitoring of displacements and micro-cracking. The DIC results that were obtained for the free shrinkage specimens showed good correlation with results obtained by traditional LVDT measurements. Micro-cracking was detected on the surface of the restrained specimens by the DIC technique, which was subsequently compared with microscopic measurements. Good correlation between the respective methods was found and it was concluded that the DIC technique is a strong tool for detection of shrinkage-induced surface cracking. 
Nevertheless, the technique has only been used in a few studies on the early-age behaviour of cement-based materials, because of difficulties related to the creation of a high-contrast surface pattern when the material is still fresh and the presence of bleeding water on the surface $[28,33]$. The speckles may move or get absorbed on the wet surface, which can result in a blurred speckle pattern with low contrast between black and white colors. The quality of the highcontrast surface pattern is known to be closely related to the correlation precision of the image and is therefore essential for the quality of the DIC post-processing $[36,43]$. High-contrast surface patterns at macro- or meso-scale are usually achieved by applying a white-coloured base layer and a black speckle pattern using spray bottles or air brushes [43]. Previous studies have used various strategies to construct such a pattern. Zhao [15,30] used spray paint to create the pattern on a fresh concrete surface, but observed a decrease in evaporation rate in the first $3 \mathrm{~h}$ after the start of mixing. Dzaye et al. [33] that studied the free plastic shrinkage behaviour of cement paste by 3D-DIC from 15 min after casting also used spray paint to first create a white base layer before applying black ink dots by spraying from a distance. A significant decrease in water evaporation was observed during the entire test period. The choice of spray paint type is considered to be highly relevant, because plastic shrinkage cracking is associated with rapid surface drying in the first hours after casting [44]. In other studies by Dzaye et al. [45,46] using a similar test setup as in [33] but different materials for creation of the high-contrast surface pattern, the white base layer was applied with a layer of aluminium oxide powder and black speckles with carbon particles distributed through a sieve. This method was reported not to be influenced by the layer of bleeding water due to the density of the materials used for the speckle pattern, but no information on the surface evaporation was given. Another strategy was applied by Ghourchian et al. [28,47] who placed small wire meshes on top of the specimen surface instead of applying surface painting to allow the presence of bleeding water and to avoid the paint slowing the evaporation rate. This technique was adequate due to the type of the mould and restraints causing a localized stress field above the triangular stress riser [6], but would not be suitable for more stochastic crack patterns with unknown locations as the ones obtained in the present study. In the present study, spray-painting the specimen surface was considered to be the most appropriate method for analysing scattered crack patterns, although it resulted in some limitations in the design of the specimen material and the geometry. To analyse the influence on the evaporation rate, different paint types, including acrylic-based and chalk-based paints, were evaluated in this study by monitoring the weight loss from mortar specimens. 


\begin{tabular}{cccc}
\hline Material & Type & Quantity $\left[\mathrm{kg} / \mathrm{m}^{3}\right]$ & Proportions \\
\hline Cement & CEM I 52.5 N & 700 & 1.0 \\
Fine aggregate & Sand $(0-4 \mathrm{~mm})$ & 1032 & 1.47 \\
Water & Tap water & 350 & 0.5 \\
\hline
\end{tabular}

\section{Experimental programme}

\subsection{Materials}

The main objects of the experimental programme were a mortar overlay and, in the restrained tests, a concrete substrate. The mortar's basic raw material properties are shown in Table 1. A low sand-to-cement ratio for the mortar overlay was chosen to foster plastic shrinkage deformations and the mix proportions were chosen in an attempt to produce results comparable to other studies that have investigated plastic shrinkage cracking $[1,20,48,49]$.

The mixing of the mortar material was carried out in a Hobart-type paddle mixer. The sand and cement were dry-mixed for $2 \mathrm{~min}$, whereupon water was added (time zero $=\mathrm{t}_{0}$ ) and wet-mixed for $3 \mathrm{~min}$ at low speed and $5 \mathrm{~min}$ at high speed. Specimens used for both free and restrained shrinkage tests and for monitoring the temperature and weight loss were cast by applying the fresh mortar into the respective moulds and using a vibration table at $60 \mathrm{~Hz}$ for up to $1 \mathrm{~min}$. A smooth steel trowel was used to finish the surface of the fresh mortar under continuous vibration. The total casting process took approx. $15 \mathrm{~min}$ from start of wet-mixing $(\mathrm{t}=15 \mathrm{~min})$.

\section{Plan view: Shrinkage moulds}

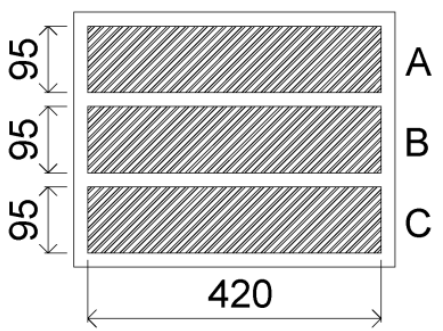

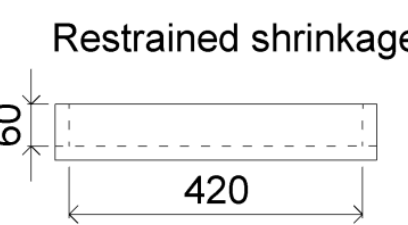

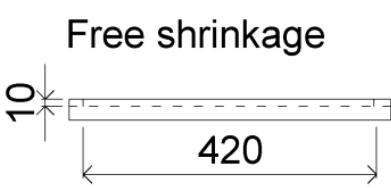

\section{Restrained mortar overlay}

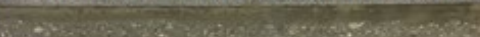

Restraining concrete substrate

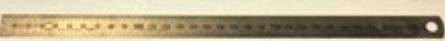

Free mortar specimen

Fig. 1. Geometry of moulds and specimens for free and restrained shrinkage tests. 


\section{Front view:}

Shrinkage test setup

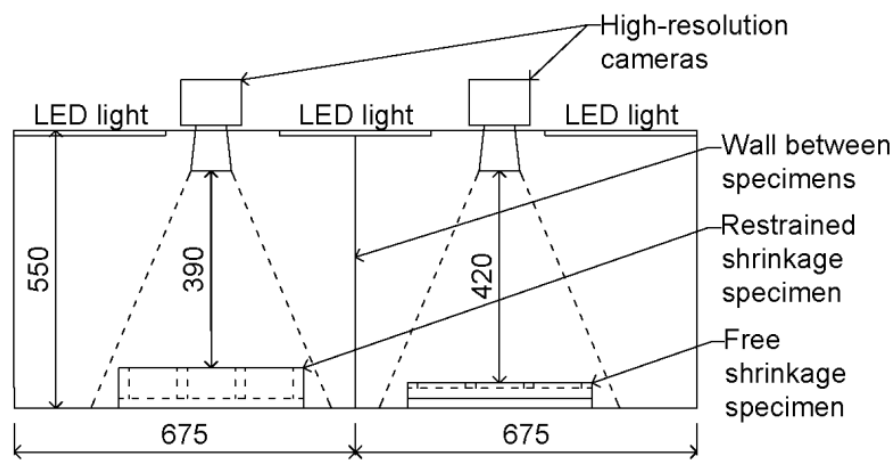

Side view:

Shrinkage test setup

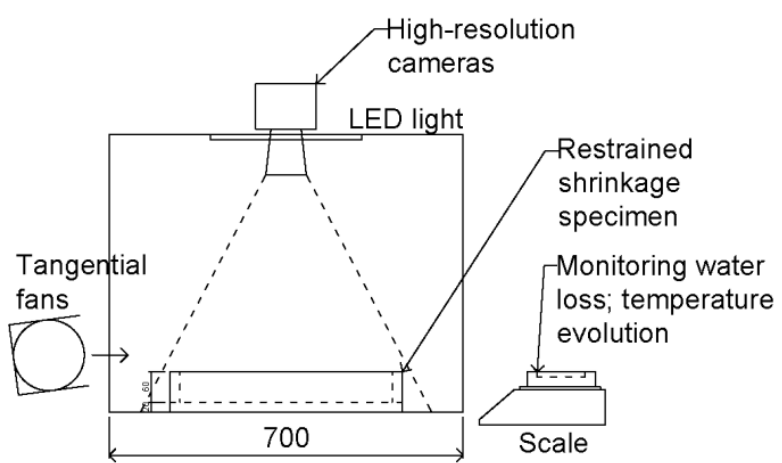

Fig. 2. Test setup using a 2D image acquisition system placed inside a climate-controlled chamber.

\subsection{Shrinkage tests}

Experiments on the plastic shrinkage behaviour of free and restrained mortar specimens were carried out and a contactless DIC technique was applied. The specimens were monitored continuously in the period of $\mathrm{t}=1-25 \mathrm{~h}$, capturing information about the formation of surface displacement and cracking over time. For the restrained shrinkage test, a fresh mortar overlay measuring $420 \times 95 \times 10 \mathrm{~mm}$ was cast on top of a concrete substrate produced in accordance with UNI/EN 1339 (2003) [50] with the desired roughness, see Fig. 1. The developed method was inspired by several studies on shrinkage cracking of cement-based materials restrained by an underlying hardened substrate $[3,12-$ 14,16,48,51]. The geometry and mixture design of the restrained mortar overlay was chosen in order to have limited bleeding water so that a high-contrast surface pattern for the DIC monitoring could be applied on the overlay surface shortly after pouring the fresh mortar overlay. Moreover, the geometry of the restrained mortar overlay was designed to promote scattered surface cracking, which would be challenging to measure quantitatively with manual measuring techniques.

The concrete substrate surface was roughened using a needle hammer to a depth of about $1 \mathrm{~mm}$ to restrain the mortar overlay during the plastic shrinkage period and cause the formation of plastic shrinkage surface cracking. The concrete substrates were cut into beams with a length of $418 \pm 0.3 \mathrm{~mm}$, a width of $93.5 \pm 0.2 \mathrm{~mm}$, and a height of $49.6 \pm 0.2 \mathrm{~mm}$, which fit into plywood moulds with the dimensions 420 x 95 x $60 \mathrm{~mm}$ and were then kept in the climate-controlled chamber until they were used. The compressive strength of the substrates was tested in accordance with UNI/EN 12390-3 (2012) [52] on cylinders measuring $50 \mathrm{~mm} \times 100 \mathrm{~mm}$ cut out of the concrete plates and was found to $35.5 \pm 6$ $\mathrm{MPa}$ and the dry density to $2.180 \mathrm{~kg} / \mathrm{m}^{3}$. Prior to each test series, three concrete substrates were wetted and positioned 
inside the moulds. After the shrinkage tests, the surface cracking (i.e. crack widths) was analysed using an optical microscope to compare the results obtained by the DIC measurements. Some of the tested overlay-substrate specimens were subsequently impregnated with fluorescence epoxy and cut into longitudinal cross-sections to measure the internal crack width and depth of cracks appearing along these longitudinal sections.

The free shrinkage behaviour was measured on mortar specimens measuring $420 \times 95 \times 10 \mathrm{~mm}$, a geometry similar to the mortar overlay used in the restrained shrinkage tests. The free shrinkage specimens were placed inside lubricated moulds with a smooth surface avoiding any restraints. Three test series (Series 1-3) were conducted to confirm the reproducibility of results from the proposed setup; each test consisted of three free shrinkage specimens, three restrained shrinkage specimens, and two smaller specimens used to monitor the temperature evolution and evaporation rate.

\subsubsection{Temperature and evaporation rate}

The internal temperature and water evaporation rate of the mortars used for the shrinkage test were monitored on smallsize unrestrained mortar specimens measuring $95 \times 95 \times 10 \mathrm{~mm}$ using thermocouples and by measuring weight loss over time $(\mathrm{t}=1-25 \mathrm{~h})$. These small-size specimens were prepared in the same way as the shrinkage specimens and were placed next to the shrinkage specimens during the tests.

\subsubsection{Climate-controlled chamber and plastic shrinkage test setup}

The setup shown in Fig. 2 for the DIC acquisition was placed inside a climate-controlled chamber without any natural light and with a temperature of $32 \pm 1.5{ }^{\circ} \mathrm{C}$ and a relative humidity of $33.5 \pm 5 \%$, which were documented every $15 \mathrm{~min}$ by a data logger. The relative humidity was controlled by a dehumidifier, and electric tangential fans were placed in front of the specimens to ensure a constant wind flow over the specimen surfaces of 3.9-4.5 m/s parallel to the $x$ direction. The wind flow was measured right above the specimen surface at different locations (front, middle, back) and was consistent for all three test series. The climatic parameters were set to ensure an adequate rate of water evaporation from the fresh mortar specimens [44] and they were close to the standard parameters suggested in ASTM C1579-13 (2013) [6].

\subsection{Specimen preparation for DIC monitoring}


The main factors influencing the quality of the displacement measurements by DIC are the quality and resolution of the camera, the lighting conditions, the high-contrast surface pattern, and the correlation software [37]. The same camera and light settings were applied for all three test series, so the accuracy of the DIC computation depended mostly on the quality of the high-contrast surface pattern, which was applied manually for each specimen. The plastic shrinkageinduced surface displacements correlate closely with the rate of water evaporation from the specimens, so the effect of the paint on the evaporation rate is crucial. The influence of both an acrylic-based and a chalk-based paint types was investigated to evaluate their effect on the rate of water evaporating from the specimen surface. The weight loss of specimens with four variations of surface preparation was measured; a) no paint; b) base of white chalk-based with dots of black chalk-based paint; c) base of white chalk-based with dots of black acrylic-based paint; d) base of white acrylicbased paint. The specimens were cast in cylindrical plastic containers with a surface area of $100 \mathrm{~cm}^{2}$ and a volume of $0.47 \mathrm{~L}$. Three replicates were tested. It should be noted that the dimensions of the containers used in this test were not the same as those used during the actual shrinkage test series, so the results cannot be directly compared.

The surface preparation for the specimens used for the evaluation of the types of surface paintings and the actual shrinkage specimens were done in the same way: After casting (at $\mathrm{t}=15 \mathrm{~min}$ ), the specimens were left at $20 \pm 3{ }^{\circ} \mathrm{C}$ for $30 \min (t=15-45 \mathrm{~min})$, after which they were painted with the respective paint types $(\mathrm{t}=45-55 \mathrm{~min})$. The specimens were then transferred to the climate-controlled chamber and placed inside the test setup (at $\mathrm{t}=55 \mathrm{~min})$ and at exactly $\mathrm{t}=$ $1 \mathrm{~h}$ the respective monitoring was initiated (weight loss, temperature or image capturing for DIC). The monitoring continued until $\mathrm{t}=25 \mathrm{~h}$.

\subsection{Monitoring of plastic shrinkage deformations using DIC}

The test setup shown in Fig. 2 was arranged in the climate-controlled chamber with a coherent light source of LED panels at the top of the chamber to limit optical noise. Two optical cameras with wide-angle lenses were mounted parallel to the surface of the specimens so that $2 \mathrm{D}$ displacements in the plane of the specimen surface could be captured. Vertical deformations were not taken into account due to the low thickness of the specimens. The distance between the lenses and the specimen surface ranged between $390 \mathrm{~mm}$ and $420 \mathrm{~mm}$, depending on the type of specimen being tested (free or restrained). The digital cameras used have a resolution of 7360 x 4912 pixels and monochrome colour representation. The respective pixel lengths were $0.087 \mathrm{~mm}$ for the free shrinkage specimens and $0.080 \mathrm{~mm}$ for the restrained specimens (a difference due to the camera lens-to-specimen distance). The cameras recorded a larger area than the size of the specimen surface in order to avoid edge effects, and the focus was on the centre of the three 
specimens. The use of two cameras allowed the testing of two moulds containing three specimens each during each test series (restrained and free specimens).

The DIC software GOM Correlate Professional 2016 was used for the DIC analysis. Images of the specimen surface were first consistently modified in ImageJ to improve contrast and brightness prior to being imported to the DIC software. The first image captured at $\mathrm{t}=1 \mathrm{~h}$ was defined as the undeformed image (reference image), and subsequent images captured every $30 \mathrm{~min}$ were compared to the reference image to compute the displacement fields. The DIC software was used to define a region of interest (ROI) for each specimen surface (95 x $420 \mathrm{~mm})$, which was virtually meshed into subset elements with a size of 20 pixels and a point-to-point distance of 15 pixels. A lower subset size and point distance would result in better data acquisition, but the speckle pattern would have to be of a density allowing a minimum of 2-3 dots in each subset [37]. Each specimen surface consisted of approximately 30,000 facets in the restrained shrinkage tests, and approximately 26,000 facets in the free shrinkage tests. The mesh fineness for each ROI is in agreement with the recommendations by Sutton et al. [37] and, moreover, it corresponds to the number of subsets used in the study by Némoz-Gaillard et al. [29] who also studied plastic shrinkage cracking of cement-based materials.

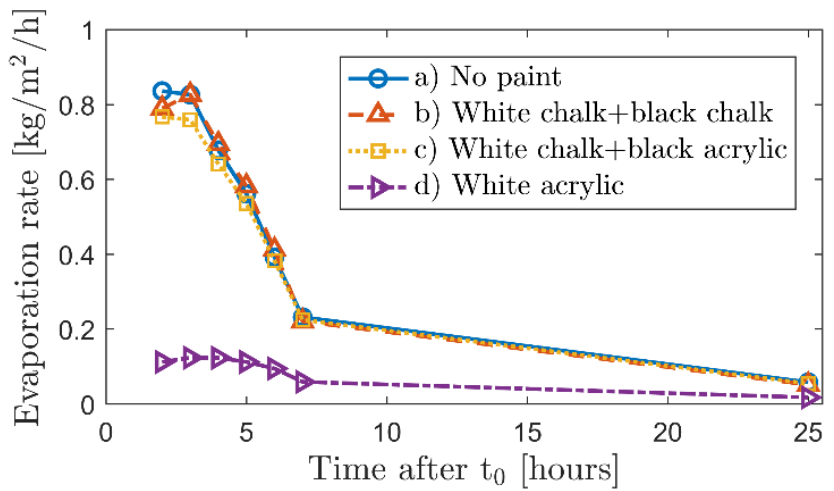

Fig. 3. Water evaporation rate from mortar specimens prepared with different types of surface paintings; a) Reference with no paint;

b) base of white chalk-based with dots of black chalk-based paint; c) base of white chalk-based with dots of black acrylic-based paint; d) base of white acrylic-based paint.

\section{Results}

\subsection{Evaluation of evaporation rate for different types of paint used for surface preparation}

The weight loss of unrestrained mortar specimens prepared with different types of surface painting used for creation of a high-contrast surface pattern for the DIC analysis was monitored during the test period of $\mathrm{t}=1-25 \mathrm{~h}$. The results were used for evaluating the influence of chalk-based and acrylic-based paint types on the evaporation rate and are illustrated 
in Fig. 3. From the figure it is seen that the application of white acrylic-based paint (type d) clearly causes a significant delay in water evaporation when compared to the reference specimen with no paint (type a), whereas the chalk-based paint (type b), which is diffusion-open, performed similarly to the reference without surface painting. Specimens with a white layer of chalk-based paint and black dots of acrylic-based paint (type c) had a slightly lower evaporation rate. This was probably due to the sealing effect of black acrylic-based paint, and the difference was clear although only a very thin layer of black acrylic-based dots was applied. When examining the specimens during and after the evaporation test, the layer of white acrylic-based painting (type d) detached from the mortar surface by flaking off. It was therefore concluded that acrylic paint is unsuitable as surface paint for plastic shrinkage testing because it seals the mortar surface and significantly delays the water evaporation. Based on these observations, it was found best to use the chalk-based paint for both the white base and the black speckle pattern (type b), although it would not allow testing materials with excessive bleed water. The use of a chalk-based paint, which doesn't influence the evaporation rate is a major achievement for the application of the DIC technique for studying the shrinkage-related behaviour of cement-based materials, since a delay in water evaporation may also delay air penetration and would probably reduce the degree of plastic shrinkage in a concrete specimen [53].

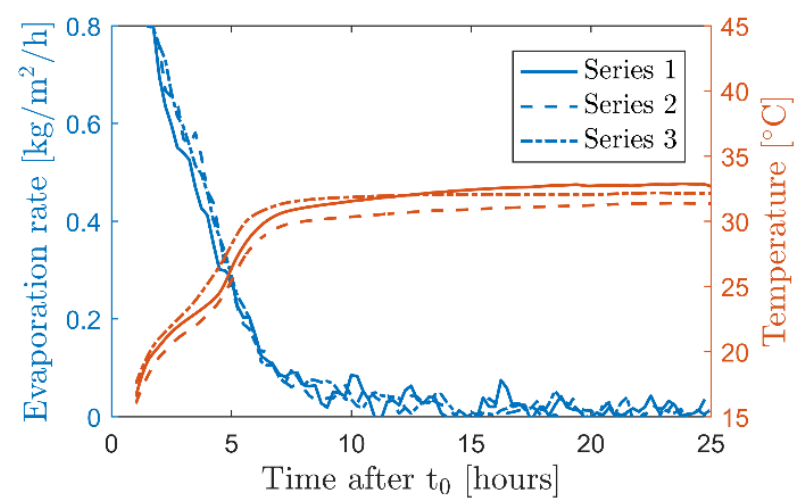

a)

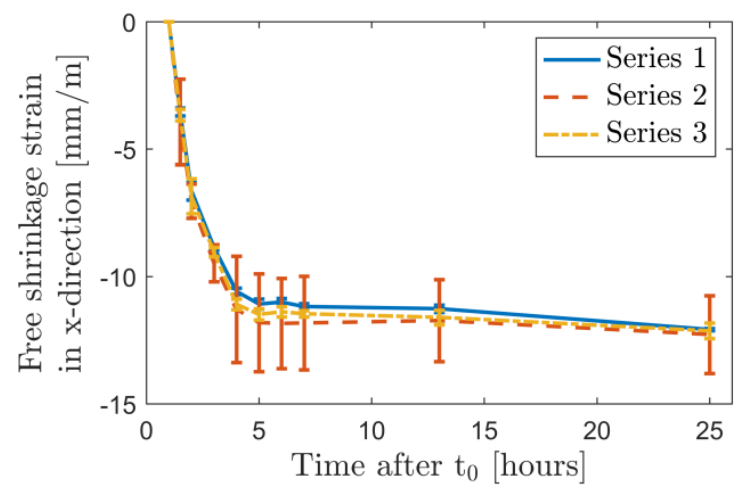

b)

Fig. 4. a) Evaporation rate and temperature evolution for mortar specimens in Series 1-3 (data is smoothened); b) In-plane free shrinkage strain in $x$-direction with mean values of three replicates $(A-C)$.

\subsection{Temperature evolution and evaporation rate during shrinkage tests}

The temperature evolution and water evaporation rate from unrestrained mortar specimens were monitored parallel to the actual shrinkage test to obtain a better understanding of the material behaviour in the period of $\mathrm{t}=1-25 \mathrm{~h}$, see Fig. 4a. The evaporation rate was approximately $0.8 \mathrm{~kg} / \mathrm{m}^{2} / \mathrm{h}$ directly after placing the specimens in the harsh environment 
of the climate-controlled chamber, whereupon it gradually decreased and stabilized at $0 \mathrm{~kg} / \mathrm{m}^{2} / \mathrm{h}$ at approximately $\mathrm{t}=9$

h. Estimations of the evaporation rate based on Menzel's formula and the nomograph in ACI 305R-06 [44,54] were calculated in the range of $0.1-0.5 \mathrm{~kg} / \mathrm{m}^{2} / \mathrm{h}$ depending on the fresh concrete temperature $(17-26 \mathrm{C}$. The cement hydration entered the acceleration period at about $\mathrm{t}=4-5 \mathrm{~h}$ after $\mathrm{t}_{0}$, which was also the end of the dormant period. The internal temperature evolution of the mortar specimens is also illustrated in Fig. 4. The initial temperature of the fresh mortar was $17 \pm 2 \mathrm{C}^{\circ}($ at $\mathrm{t}=1 \mathrm{~h})$. The temperature and evaporation curves for the specimens monitored during the series of Series 1-3 showed a similar shape for all three test series.

\subsection{Study of free shrinkage behaviour using DIC}

The free shrinkage behaviour of mortar specimens measuring 420 × 95 x $10 \mathrm{~mm}$ was monitored from $\mathrm{t}=1-25 \mathrm{~h}$. Most significant plastic shrinkage deformations took place in the $x$-direction due to the specimen geometry and wind exposure. Uniform displacement fields were observed and by using the data obtain by the DIC monitoring, the horisontal displacement during the entire test period was quantified. Equivalent displacement and strain data in the centre of each subset were computed as the average value over the subset area $(20 \times 20$ pixels $)$ [28]. With the $x$ direction being parallel to the length of the specimens, the maximum free shrinkage strain $(\mathrm{mm} / \mathrm{m})$ in this direction over time was computed using a Matlab routine. This is illustrated in Fig. 4b, where each graph represents the mean value of three specimens tested in each of the respective tests. The free shrinkage strain (contraction) increased rapidly during the first 3-4 hours after $t_{0}$ and then stabilized. Final contractions of the specimens were in the range of approximately 5 $\mathrm{mm}$ (relative contraction $=-12 \mathrm{~mm} / \mathrm{m}$ ) in the $x$-direction for all specimens tested. Due to the specimen geometry and the oriented wind flow, focus was solely on the shrinkage behaviour in the $x$-direction. 
a) Strain by DIC in $\mathrm{x}$-direction at $\mathrm{t}=25 \mathrm{~h}$

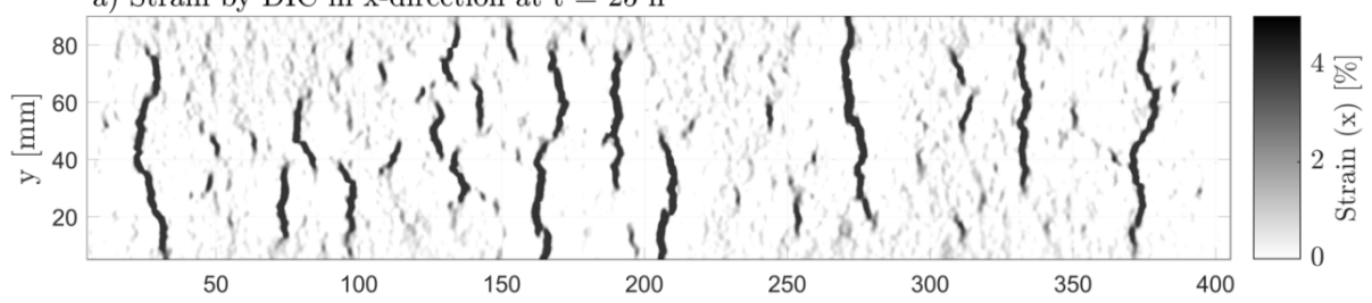

b) Strain by DIC in y-direction at $\mathrm{t}=25 \mathrm{~h}$

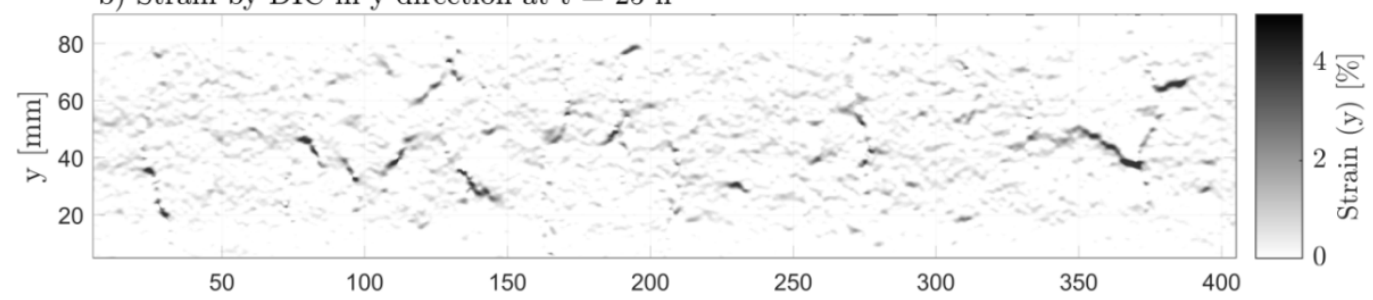

c) Strain by DIC in (x,y)-direction at $\mathrm{t}=25 \mathrm{~h}$

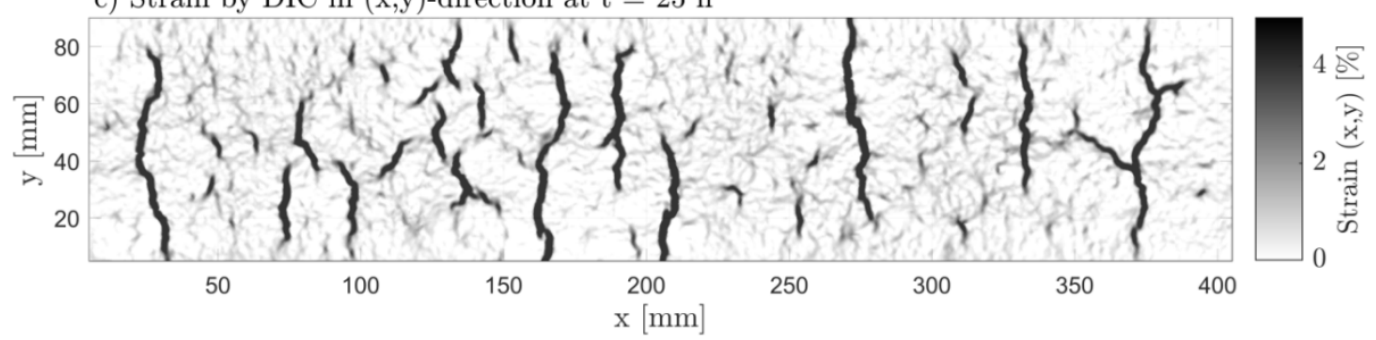

Fig. 5. Surface strain fields for Specimen C, Series 2, in: a) x-direction; b) y-direction; c) Major (x,y)-direction

\subsection{Study of surface cracking in restrained overlays using DIC}

The aim of this section is to quantify the degree of cracking in the restrained mortar overlays in terms of time of cracking, crack location, crack width, crack length, and crack area. During the restrained shrinkage test of the mortar overlays $(\mathrm{t}=1-25 \mathrm{~h})$, several visible surface cracks formed. The displacement and strain fields were obtained using the DIC software, and the crack formation was then analysed using a numerical routine for post-processing of the DIC data.

Since the strain data is a numerical approximation to partial derivatives of the displacement (Eq. 1), abrupt changes in displacement are simultaneously illustrated as local extrema in strain. These peaks in strain and sudden gaps in displacement reveal surface cracking [55]. From small-deformation theory, the strain tensor is given component-wise by:

$$
\varepsilon_{i j}=\frac{1}{2}\left(\frac{\partial u_{i}}{\partial x_{j}}+\frac{\partial u_{j}}{\partial x_{i}}\right)
$$

where $u$ is the displacement and $x$ is the position vector. 
Based on the assumption that most cracking appear in the $x$-direction and for simplicity, the numerical post-processing of the DIC data was restricted to the in-plane displacement and strain in the $x$-direction for the analysis of surface cracking. Considering only the strain in the $x$-direction gives:

$$
\varepsilon_{11}=\frac{\partial u_{1}}{\partial x_{1}}
$$

290 This effectively reduces the analysis to a one-dimensional problem for each linear segment parallel to the $x$-axis. The 291 purpose here is to prove that useful results can be obtained by projecting the data onto just one of the axes when the 292 cracks are evenly oriented. While similar numerical processing would be possible in the full 2D case, one-dimensional analysis was preferable due to its simplicity both in data processing and in the explicability of the method. To describe the post-processing procedure for the computation of the crack data Specimen C, Series 2 is used as an example in the following figures. Fig. 5a-c show the strain data obtained by DIC for the normal strain in the $x$-direction, $y$-direction, and major $(x, y)$-direction. The figure clearly demonstrates the ability of the DIC technique to localize areas with increased strain, i.e. the boundaries of the cracks. In this case, it is clear that the numerically largest normal strain values are parallel to the $x$-direction, which was the case for all 9 specimens tested (Series 1-3, Specimens A-C). This is likely due to the specimen geometry and wind flow orientation. 
a) Original image at $\mathrm{t}=25 \mathrm{~h}$

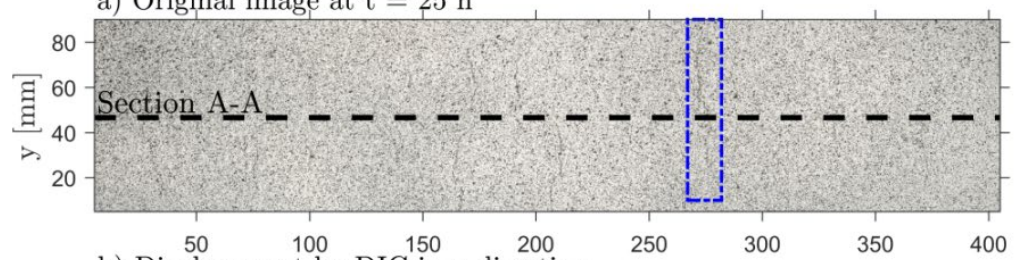

b) Displacement by DIC $\stackrel{150}{50} \stackrel{200}{\text { in }}$-direction

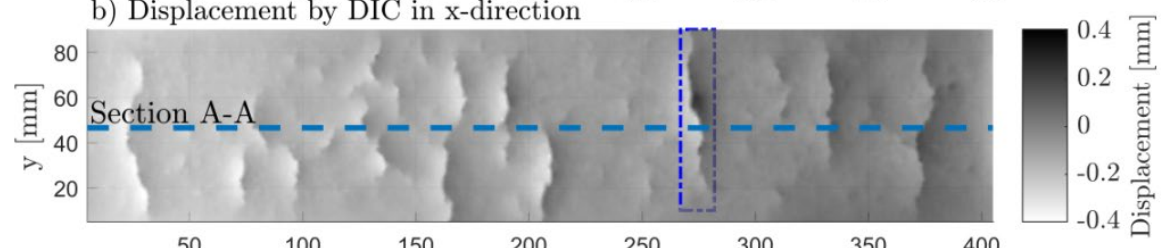

c) Strain by DIC in x-direction
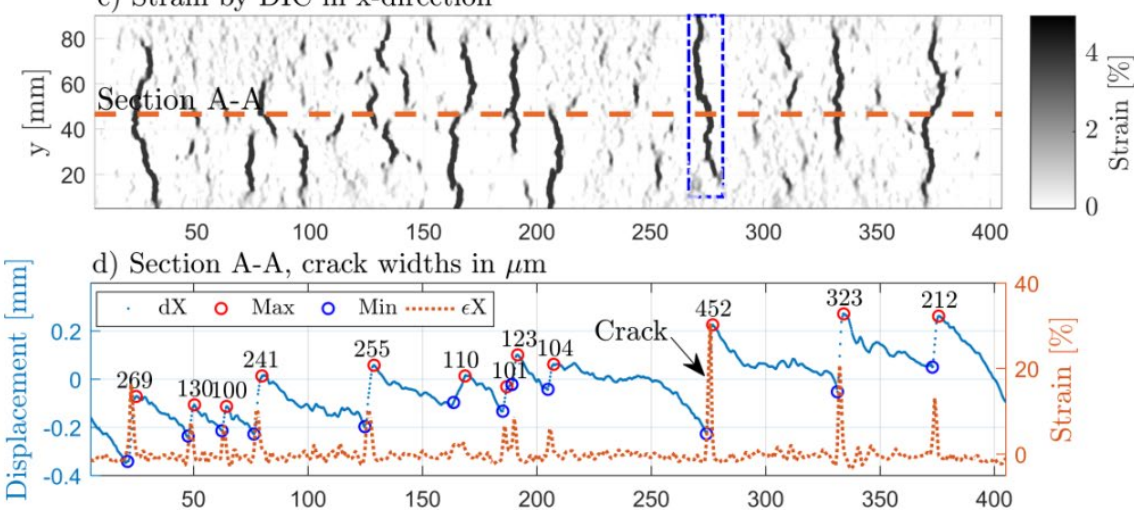

e) Cracks synthesized from DIC data

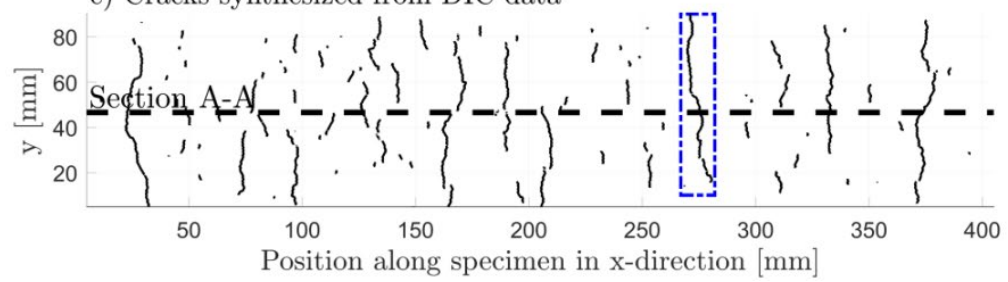

Fig. 6. Restrained mortar overlay (Specimen C, Series 2) at $t=25$ h. a) Original image; b,c) In-plane surface displacement and strain in x-direction by DIC data; d) In-plane surface displacement and strain by DIC data along Section A-A showing detected cracks; e) Crack pattern synthesized from data by the post-processing approach. A magnification of the rectangular area around a large crack is shown in Fig. 7.

\subsubsection{Computation of surface cracking based on DIC data}

The first part of the post-processing procedure was to export an array consisting of $(x, y)$ coordinates for all subsets in the ROI for each specimen surface and the corresponding displacement and strain data for further analysis in Matlab. The data in each ROI was interpolated onto a rectangular grid with point-to-point distance of $0.25 \mathrm{~mm}$ in both $x$ - and $y$ directions, which ensures uniformity in the grid, enabling estimation of derivatives and visualizations of the data. In total, there are approximately 380 one-dimensional sections parallel to the $x$-direction per specimen surface. Fig. $6 \mathrm{a}-\mathrm{c}$ 
show an image of the cracked surface of Specimen C, Series 2, at $t=25 \mathrm{~h}$, and surface displacement and strain fields parallel to the $x$-direction as calculated by DIC. A selected section, Section A-A, along the specimen surface going through the centre of the specimen is marked with a dashed line is shown in Fig. 6d.

The post-processing procedure used for automated detection of surface cracking can be explained by Fig. 6d, which shows the surface displacements and strains in the $x$-direction along Section A-A. Damaged areas (surface cracks) are defined as local gaps in the displacement field and corresponding peaks in surface strain $[13,55,56]$. To compute these damaged areas on the specimen surface, i.e. crack widths, the local minimum values (blue circles) and the maximum values (red circles) neighbouring each displacement gap were identified for each section and corresponds to the identified crack width $\left(w_{i}\right)$.
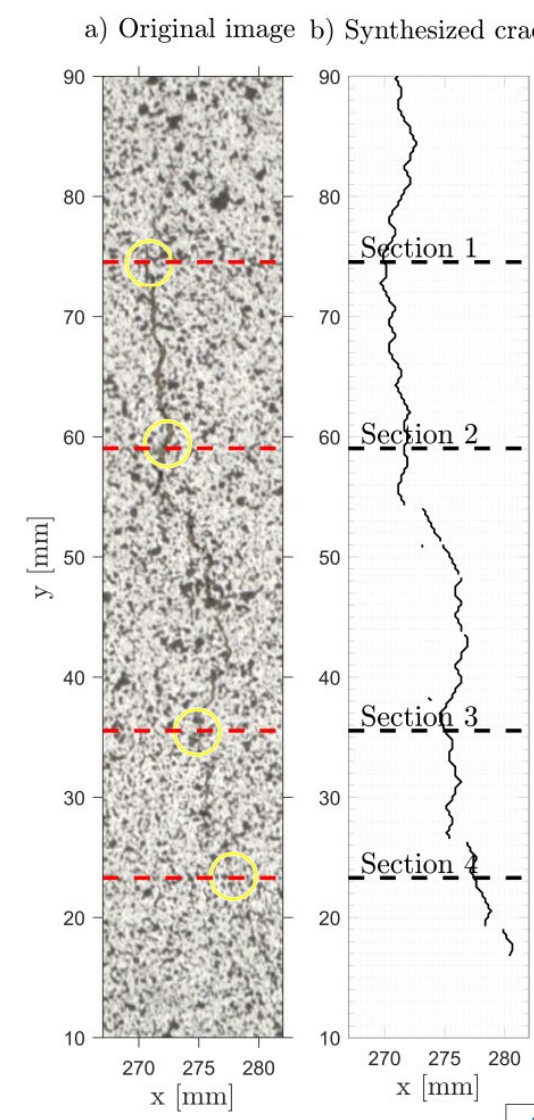

c) DIC Section 1

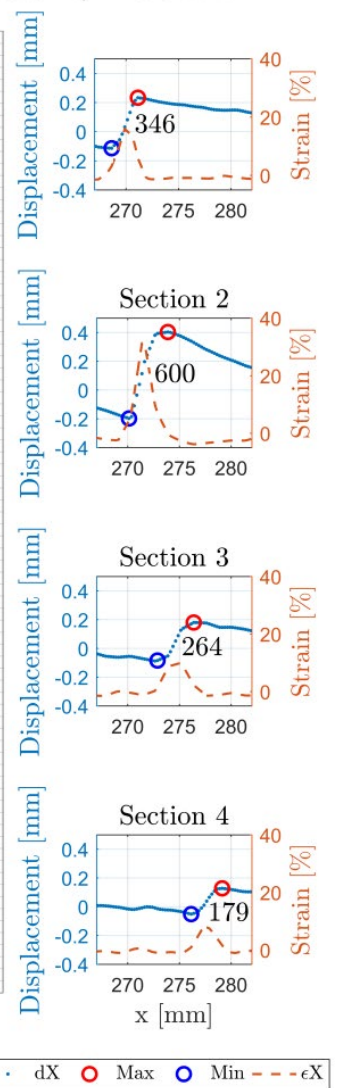

Fig. 7. Magnification of the rectangular area shown in Fig. 6 (Specimen C, Series 2, $t=25$ h): a) Original image; b) Crack pattern synthesized from DIC data by the post-processing approach; c) In-plane displacement and strain along Section 1-4.

From the strain data, a strain threshold limit for when a displacement gap is considered as cracked was defined. This threshold limit is dependent on parameters such as the material properties (the tensile strength and stiffness) under the 
specific environmental conditions and the DIC setup (the resolution of the image and subset properties), and should therefore not be interpreted as a globally applicable number. The strain threshold limit also defines the fineness of the cracks to be identified. Several strain threshold limits ranging from $0.002 \mathrm{~m} / \mathrm{m}$ and up to $0.1 \mathrm{~m} / \mathrm{m}$ were tried in an effort to find a reasonable level. See also Section 4.1. With very low threshold values, a significant number of short, very fine cracks were identified, which can be considered as noise. Lagier et al. [57] suggested a strain threshold limit based on the ratio between tensile strength and Young's modulus in compression (tensile strain capacity) [32]. In the present study, however, the surface cracking occurred when the overlay material was still fresh and changed rapidly during hardening and would be difficult to obtain at the exact time of surface cracking. Mauroux et al. [13] studied microcracking of mortars induced by drying shrinkage and defined a maximum strain threshold limit of $5 \cdot 10^{-5} \mathrm{~m} / \mathrm{m}$. Boshoff and Adendorff [56] defined a crack as having a displacement gap larger than $15 \mu \mathrm{m}$. In this study, the strain threshold limit is defined in terms of the average strain $\left(\varepsilon_{i, \text { avg. }}\right)$ along the displacement gaps between the local maximum $\left(x_{i, \max }\right.$, $\left.u_{i, \max }\right)$ and minimum $\left(x_{i, \min }, u_{i, \min }\right)$ values.

$$
\varepsilon_{i, \text { avg. }}=\frac{u_{i, \max }-u_{i, \min }}{x_{i, \max }-x_{i, \min }}
$$

Using the average strain makes the strain threshold limit less sensitive to noise than simply requiring an individual strain value to be above a certain threshold limit. On the basis of microscopy observations and the desired fineness of crack detection, a strain threshold limit was defined as $K_{0}=0.02 \mathrm{~m} / \mathrm{m}=2 \%$, such that a crack is defined as a local interval where the average tensile strain along the displacement gap is larger than $K_{0}$, i.e.

$$
\varepsilon_{i, \text { avg. }}>K_{0} \Rightarrow \text { Surface crack }
$$

Based on the section-wise analysis (sections per $0.25 \mathrm{~mm}$ ) in accordance with the above procedure, a digital reproduction of the crack pattern was synthesized including crack location and crack width. See Fig. 6e. Please note that the crack widths and locations were not derived from pixels, but from computation of DIC data. Also, the line thickness on the synthesized crack patterns in does not correspond to the real crack width, but is only illustrating the centre line for all identified cracks using standard line width for plotting.

All displacement gaps with an average tensile strain larger than $K_{0}$ were identified as cracks and crack widths were calculated corresponding to these displacement gaps along each separate section. In this way, quantified measures of the crack width along every section on the specimen surface were obtained. If cracks appeared in adjacent parallel sections, the cracks were defined as coherent whenever the distance between the cracks was below a crack coherence threshold defined as three times the distance between adjacent parallel sections. After identifying coherent cracking points (across 

crack, making it also robust to more noisy representations of cracks.

a) Original image

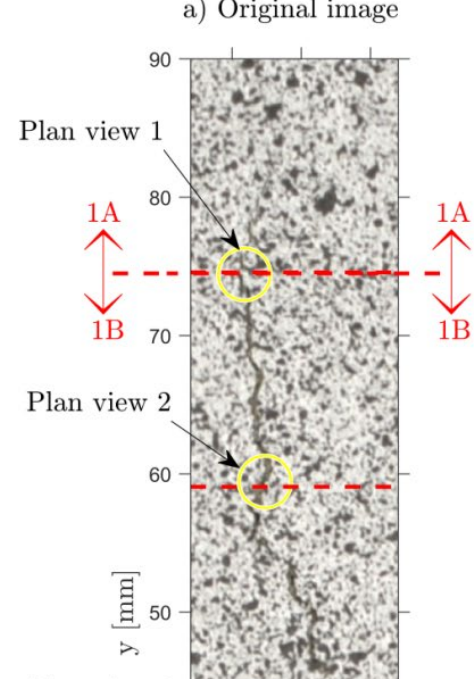

b) Plan view 1

c.w. $=320 \mu \mathrm{m}$

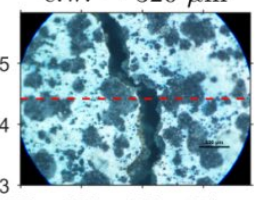

$\begin{array}{llll}268 & 269 & 270 & 271\end{array}$

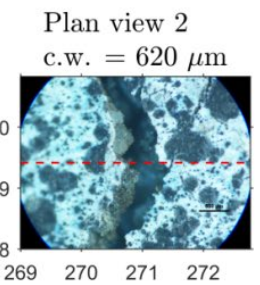

Plan view 3

40

30

Plan view 4

$20-$

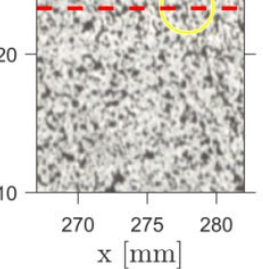

Plan view 3

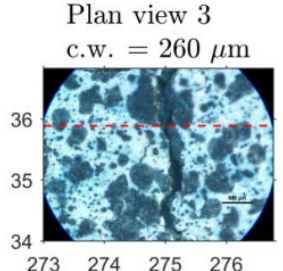

Plan view 4 c.w. $=160 \mu \mathrm{m}$

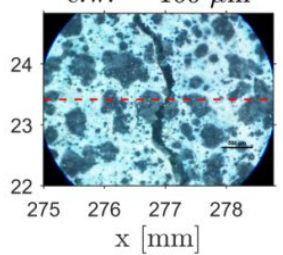

c) Section $1 \mathrm{~A}$

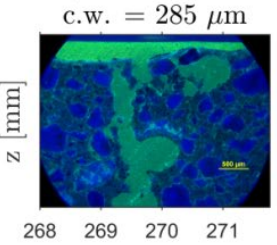

Section 2A

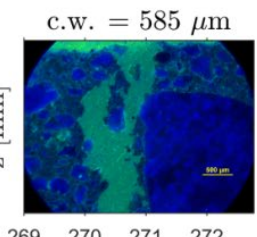

$269 \quad 270 \quad 271 \quad 272$
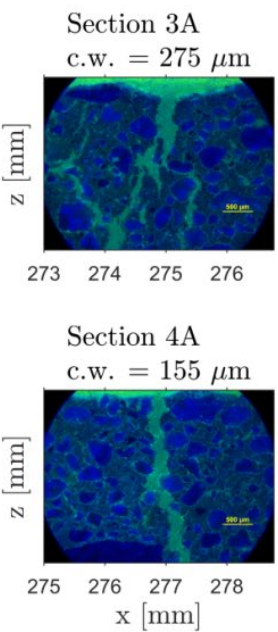

d) Section $1 B$

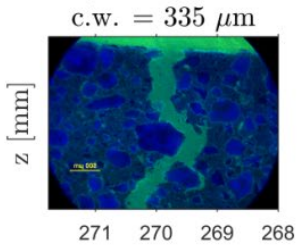

Section 2B

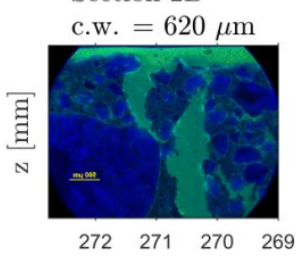

Section 3B

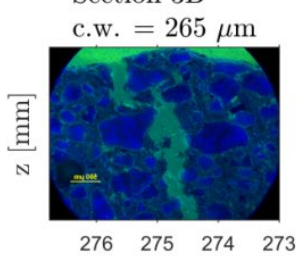

Section 4B

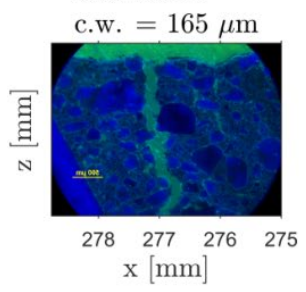

Fig. 8. Measurements by optical microscope of cracks near Section 1-4 as shown in Fig. 7 (Specimen C, series 2, $t=25$ h). a)

Original image; b) Microscopic plan views; c) Section view A-A "above" section 1-4 for epoxy-impregnated specimens; d) Section

\subsubsection{Correlation between the DIC results and microscopy measurements}

361 The crack displayed inside the rectangular area shown in Fig. 6, is magnified in Fig. 7 showing a) the original image at $t$

$362=25 \mathrm{~h} ; \mathrm{b}$ ) the computed cracks based on the post-processing procedure; c) four selected longitudinal sections crossing the crack (Section 1-4 parallel to the $x$-axis) illustrating the surface displacement and strain along each of the selected sections. The post-processing procedure described in Section 3.4.1 was used for the automated computation of the crack widths from the displacement and strain fields along Section 1-4 on the specimen surface, which in these specific cases 
are, $346 \mu \mathrm{m}, 600 \mu \mathrm{m}, 264 \mu \mathrm{m}$ and $179 \mu \mathrm{m}$, respectively, as shown in Fig. 7c. To validate the dimension of the crack widths computed based on DIC data, the crack widths along Section 1-4 were measured using an optical microscope. Examples on this is given in Fig. 8 that shows b) Plan view: microscopic images of the specimen surface in the area around the selected Section 1-4, c, d) Section views on each side of the selected section specimens to measure the crack width and depth on epoxy-impregnated samples cut into longitudinal sections as close to Section 1-4 as possible. These manual crack width measurements were done after the shrinkage test series as it would be very challenging to obtain crack measurements with this degree of precision while the shrinkage test was running.

First of all, it was observed that the crack width along the length and depth of a crack was highly irregular, which also complicated a manual quantification of the crack width. Cracks in concrete are usually highly irregular and continuously change direction as they propagate [34]. This makes them difficult to quantify with manual measuring techniques, which further demonstrates how important the DIC quantification technique is for evaluating crack patterns. Secondly, the microscopy images showed a good correlation with the crack widths measured from DIC data, both when analysing the crack widths on the specimen surface, b) Plan view; and when analysing the longitudinal sections of the epoxy-impregnated specimen, c,d) Section view.

Regarding the detected crack length, some spaces can be seen along the length of the computed crack resulting in discontinuities, although many of the cracks visually appeared to be continuous along the entire length. However, when the cracks were examined using an optical microscope, it was confirmed that the computed discontinuities were actually physically present at the detected locations along the crack. The identification of smaller crack widths is linked to the strain threshold value, so that lower strain threshold values result in the identification of finer cracks. It was also observed that parallel cracks running close to each other or the presence of fine cracks or other irregularities near the measured crack could result in calculation errors. The DIC software is unable to compute the subsets closest to a crack. Thus, the subset texture in the cracked area is being modified by the presence of the crack, which can result in overestimations of the measured crack width $[13,16]$. Another challenge arises when multiple cracks are present in one subset [58], but in the present study such crack widths were considered to be too small to include because the distance between each subset centre was $1.2 \mathrm{~mm}$ (15 pixels). Even though there is a strong correlation between the crack widths measured using DIC and the microscopy measurements, local flaws on the specimen surface could lead to local fluctuations in the correlation computation of the displacement fields [57]. The deformations were monitored while the mortar was still plastic and the following $24 \mathrm{~h}$, and large changes occurred on the surface during the test period. These 
changes included not only the plastic shrinkage, but also developments in the surface structure due to the material drying and hardening, and the emergence of air bubbles on the surface, which could lead to local flaws.

It is acknowledged that this is a simplified method for calculating the crack widths, due to the assumption that all cracks are parallel to a pre-defined axis and that the method can result in local errors in the DIC data and post-processing results. However, the proposed method is a great improvement on more manual measuring techniques and provides excessive information about the materials behaviour.
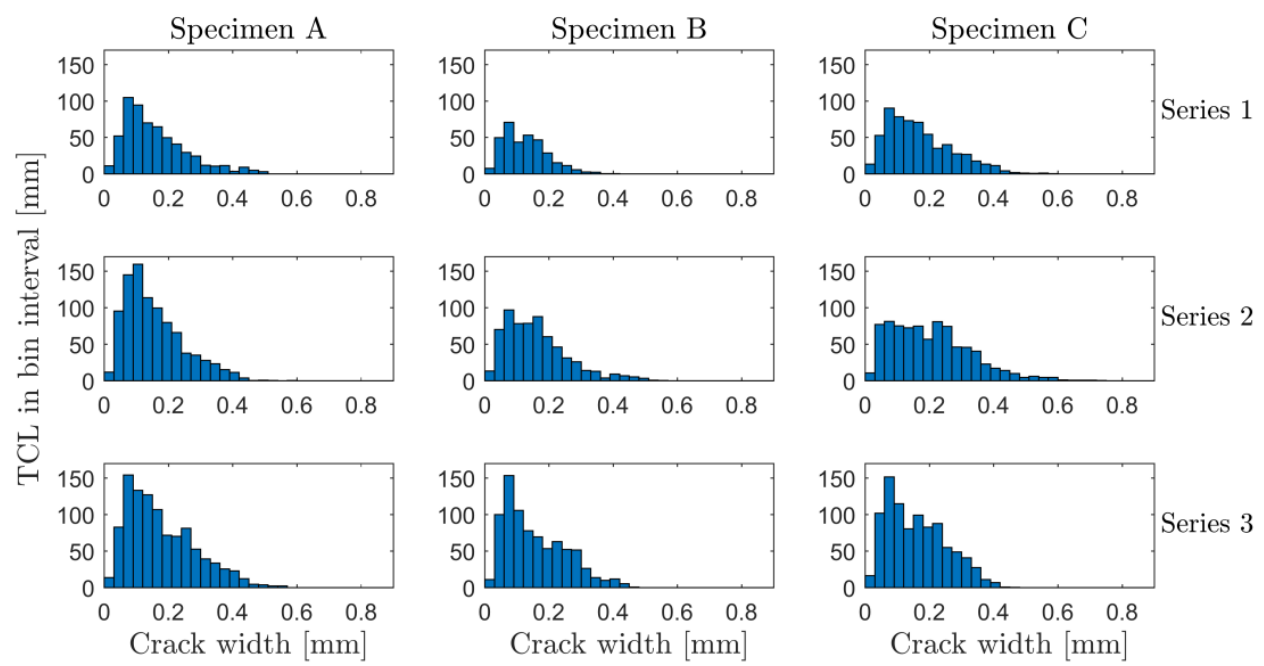

Fig. 9. Histograms of the relation between the total crack length (TCL) [mm] in each bin interval and the crack width distribution
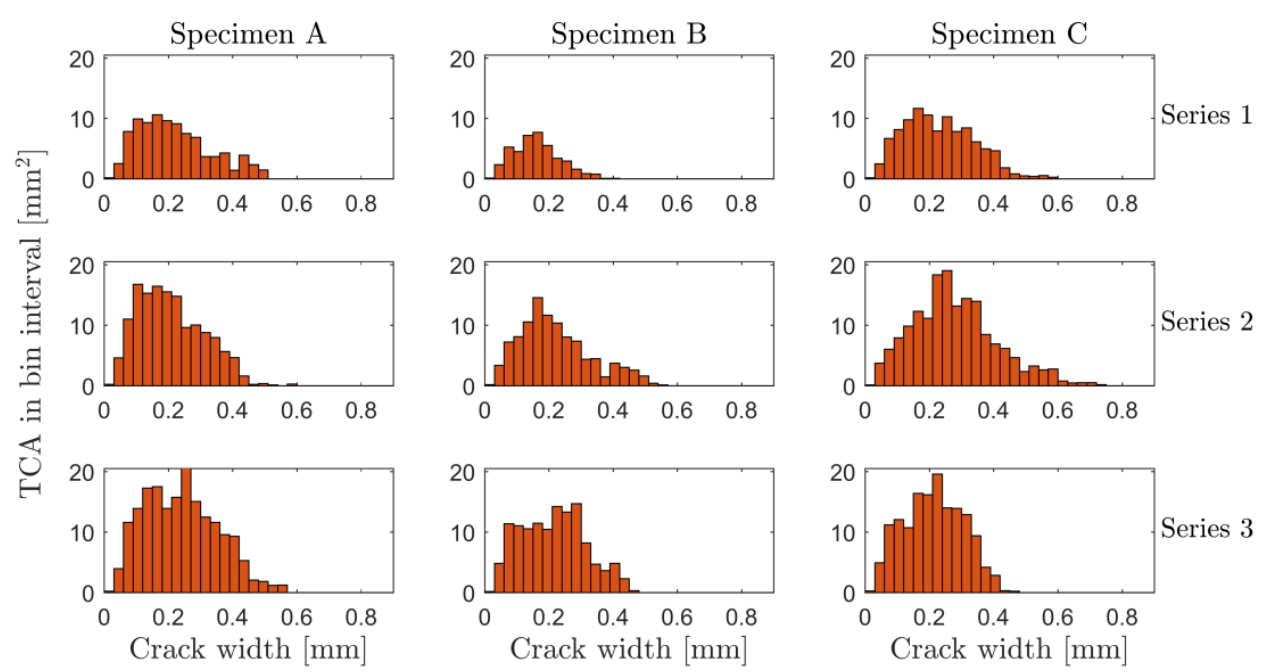

Fig. 10. Histograms of the relation between the total crack area (TCA) $\left[\mathrm{mm}^{2}\right]$ in each bin interval and the crack width distribution 


\subsection{Quantification of surface cracking}

First, all displacement gaps (cracks) with an average strain level above the strain threshold value were detected along the 380 sections parallel to the $x$-direction of the interpolated grid. Computing the crack width $\left(w_{i}\right)$ for all these cracks along every section enabled plotting of histograms showing the crack width distribution (CWD). The CWD was plotted so that each bin interval (interval of crack widths) was representing the total length of cracks (TCL) within each bin interval (Fig. 9); and as the total crack area (TCA) within each bin interval (Fig. 10). These plots are shown for all nine specimens (Series 1-3, specimens A-C). Besides the histograms, various crack parameters, such as maximum crack width, mean crack width and total crack area over the entire specimen surface, could easily be calculated using the postprocessing procedure. See Table 2 . The crack area of each $\operatorname{crack}\left(A_{i, c r}\right)$ and the total crack area $\left(A_{t o t}\right)$ of the entire surface of each specimen was calculated by summing all cracks [12].

The accuracy of these histograms depends on the number of subset properties for each specimen surface and the fineness of the interpolated grid. Since 380 sections parallel to the $x$-direction were analysed for each specimen surface, the fineness of the grid was considered to be sufficient for the purpose of this paper. Similar histograms have been used in other studies to present crack width distributions, e.g. for cracks emerging from tensile loading [56,59] or from shrinkage $[60,61]$. Traditional crack parameters used for evaluation of the degree of plastic shrinkage cracking such as maximum crack width, crack length, and total crack area are only considered as weak indicators of the degree of surface cracking. Thus, this way of representing the degree of surface cracking is considered to be more informative.

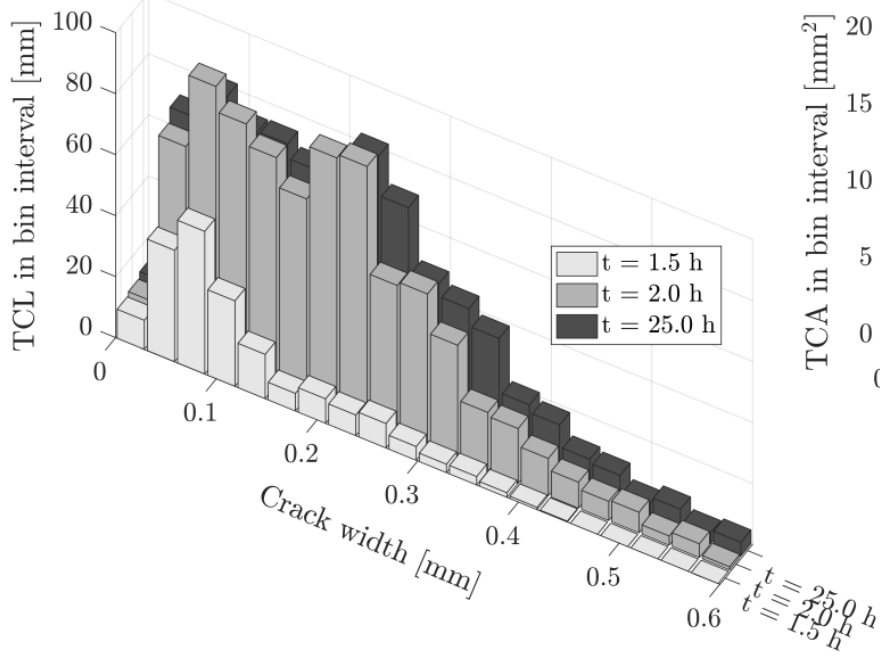

a) Total crack length per bin interval

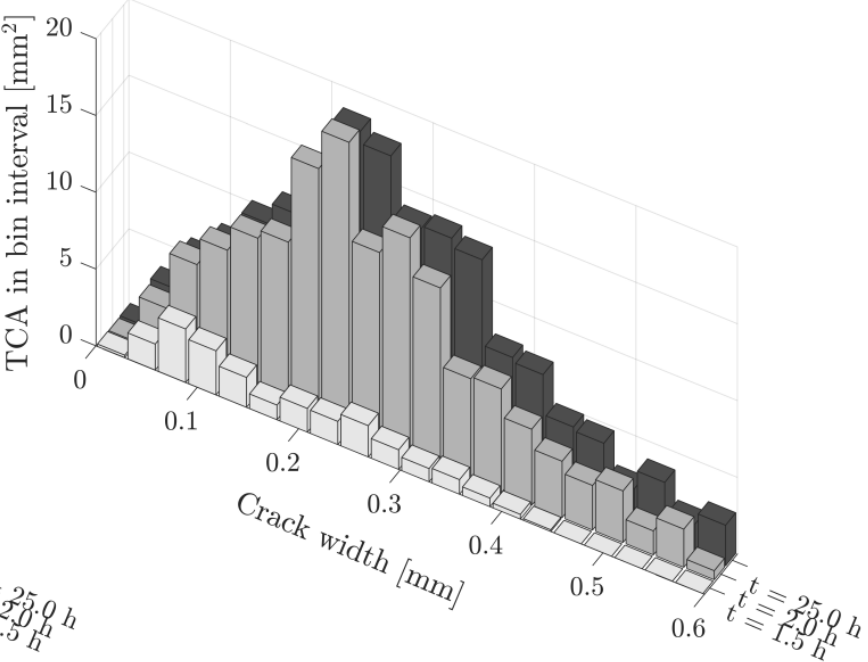

b) Total crack area per bin interval 
Fig. 11. Histograms of the relation between the crack width distribution (CWD) over the entire specimen surface and a) the total crack length [mm] and b) the total crack area $\left[\mathrm{mm}^{2}\right]$ in each bin interval, at selected time intervals of $t=1.5 \mathrm{~h}, 2.0 \mathrm{~h}, \mathrm{~h}$ and $25 \mathrm{~h}$.

\subsubsection{Crack area evolution}

430

Another advantage in using DIC for crack detection and quantification is the opportunity to study the evolution in surface cracking over time. Fig. 11 illustrates the evolution in histograms showing the crack width distribution over the entire surface area with each bin representing the total crack length and total crack area, respectively. The example is again given for Specimen C, Series 2. Initiation of the shrinkage-induced surface cracking had already happened when the first deformed image was captured at $t=1.5 \mathrm{~h}$. This reveals that the images should have been captured more frequently, especially in the beginning of the test, when the largest shrinkage-induced deformations occurred. The crack network had stabilized at the time stage of $\mathrm{t}=2.0 \mathrm{~h}$, and only slight propagations in crack widths and number of cracks were observed until the end of the test at $\mathrm{t}=25 \mathrm{~h}$ (time stages in between are not shown). These observations correspond well with the behaviour of the free shrinkage specimens, which showed most deformation activity during the same time period, although the crack network stabilized faster than the deformation in the free specimens. The initial shape of the crack network remained stable throughout the entire test, though the crack width intensity increased slightly over time.

Table 2. Summary of basic crack parameters for restrained mortar overlays

\begin{tabular}{ccccccc}
\hline Specimen & $\begin{array}{c}\text { Mean crack width } \\
{[\mu \mathrm{m}]}\end{array}$ & $\begin{array}{c}\text { SD } \\
{[-]}\end{array}$ & $\begin{array}{c}\text { Max crack width } \\
{[\mu \mathrm{m}]}\end{array}$ & $\begin{array}{c}\text { SD } \\
{[-]}\end{array}$ & $\begin{array}{c}\text { Total crack area } \\
{\left[\mathrm{mm}^{2}\right]}\end{array}$ & $\begin{array}{c}\text { SD } \\
{[-]}\end{array}$ \\
\hline Series 1 (A-C) & 151.2 & 18.7 & 497.8 & 78.2 & 87.8 & 29.6 \\
Series 2 (A-C) & 173.5 & 22.8 & 631.2 & 80.5 & 151.5 & 30.7 \\
Series 3 (A-C) & 164.9 & 8.9 & 500.0 & 45.5 & 167.5 & 26.4 \\
\hline
\end{tabular}

\subsection{Reproducibility of restrained shrinkage test}

Three identical test series (Series 1-3) were carried out on three specimens (Specimen A, B, C) to evaluate the reproducibility of the test method. All the restrained mortar overlays were of the same mix design and exposure conditions. Fig. 9-10 quantitatively illustrate the degree of surface cracking in histograms showing the crack width distribution and Table 2 gives basic crack parameters such as mean and maximum crack width, and total crack area at $\mathrm{t}$ $=25 \mathrm{~h}$. Despite some variations in total crack area between the three test series, the mean and maximum crack width are 
very much alike. It was difficult to create identical crack patterns from one specimen to another, and the formation of plastic shrinkage cracking is generally known to be a highly irregular and variable process $[3,48]$. However, the CWD for most of the specimens follows the same trend.

Since the mortar mix design used in this study was the same for all specimens tested, the factors resulting in different surface cracking behaviour mostly stem from the slight variations in environmental conditions, the geometry and surface roughness of the concrete substrate, thus the thickness of the fresh mortar layer. The environmental conditions (temperature and relative humidity) inside the climate-controlled chamber were monitored during the entire test and shown in Fig. 12. Slight variations in the relative humidity are observed with the lowest being for Series 2 , however, this still doesn't explain the lower total crack area for Series 1.
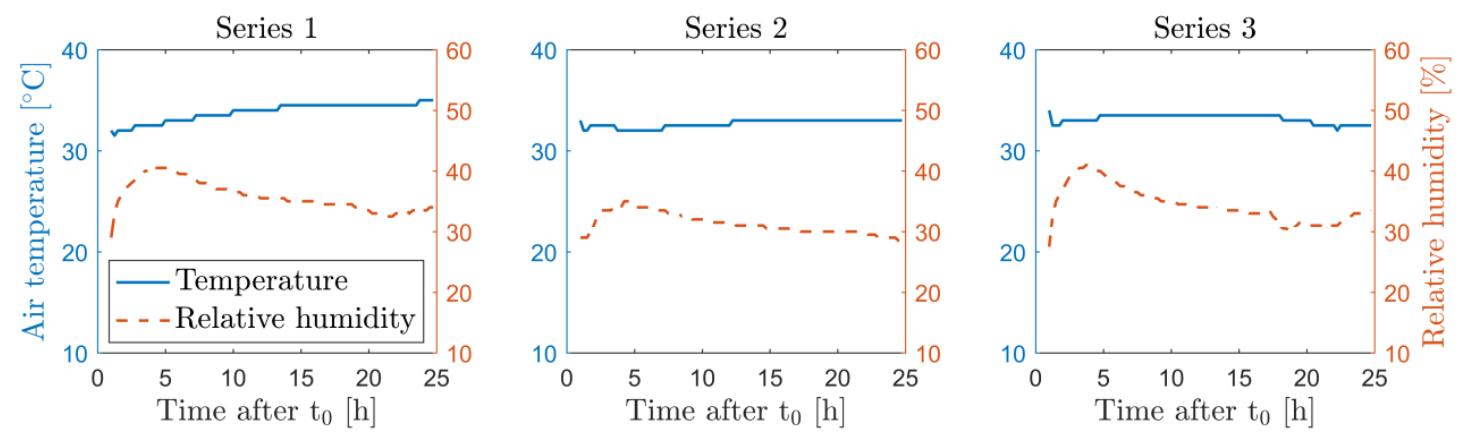

Fig. 12. Temperature and relative humidity during the shrinkage tests series, Series 1-3.

\section{Discussion}

\subsection{Evaluation of defined strain threshold limit}

The defined strain threshold limit, $K_{0}$, determines the fineness of displacement gaps that should be identified as cracks. Low threshold values would result in the detection of significantly more fine cracks with very low crack widths, where some could be due to the presence of local fluctuations or noise resulting in interpolation errors [13]. Since the highcontrast surface pattern was applied when the material was still wet, it could lead to small movements of the paint layer, application of the high-contrast surface pattern when studying plastic shrinkage cracking in cement-based with excessive bleeding water $[28,45,46]$.

The determination of a crack and its width is still a problem of definition [34], so the strain threshold value was chosen on the basis of visual inspections. Fig. 13a-c illustrate digital reproductions of crack patterns computed for Specimen $\mathrm{C}$, Series 2 , using three different strain threshold values: $K_{0}=0.002 ; 0.01$; and $0.02 \mathrm{~m} / \mathrm{m}$, respectively. It is clear that a 
strain threshold value of $K_{0}=0.002 \mathrm{~m} / \mathrm{m}$ leads to a large number of fine cracks being identified. The CWD also illustrates how many cracks with a very low crack width are identified with lower threshold values. The identification of wider cracks, i.e. the right side of the CWD, is not influenced by the strain threshold value. A strain threshold value of $K_{0}=0.02 \mathrm{~m} / \mathrm{m}$ (Fig. 13c) was chosen for this study because it only shows the widest, most well-defined cracks on the specimen surface with a minimum of identified cracks that could be considered as noise.

Fig. 14 shows the total crack area at $\mathrm{t}=25 \mathrm{~h}$ for each of the specimens (Series $1-3$, Specimens A-C) computed for strain threshold values varying from $K_{0}=0.002 \mathrm{~m} / \mathrm{m}$ to $K_{0}=0.10 \mathrm{~m} / \mathrm{m}$. It is clear that the total crack area depends entirely on the strain threshold value chosen, and the curves follow the same trend for each specimen.
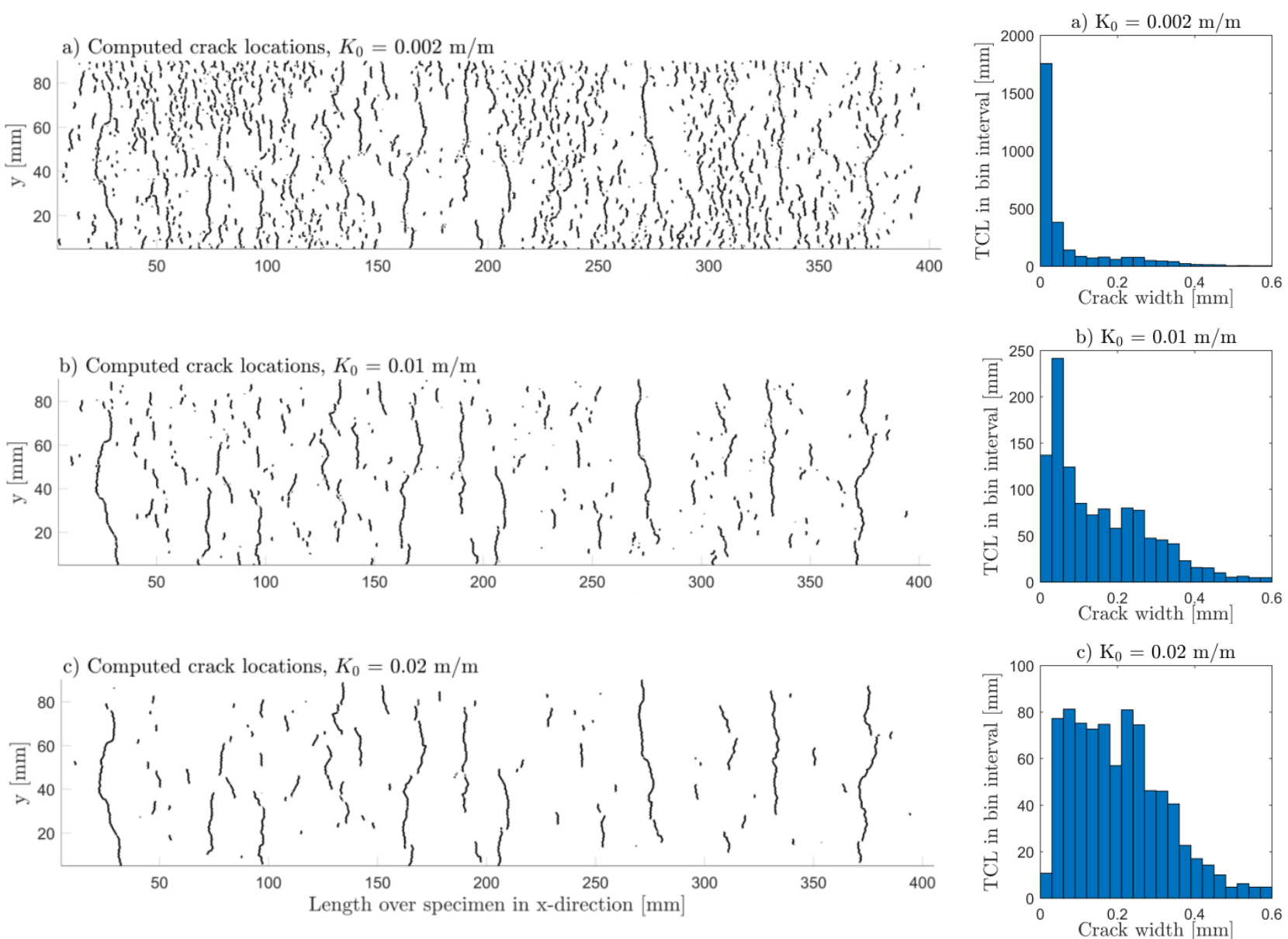

Fig. 13. Examples of crack patterns synthesized from data by the post-processing approach and histograms of the relation between the total crack length (TCL) [mm] and CWD using three different strain threshold values, $K_{0}:$ a) $\left.0.002 \mathrm{~m} / \mathrm{m} ; \mathrm{b}\right) 0.01 \mathrm{~m} / \mathrm{m} ; \mathrm{c}$ ) 0.02 
In this study, the focus was on crack openings parallel to the $x$-direction, because most surface cracking occurred in this direction. The post-processing approach is based on a section-wise inspection of parallel sections and computes displacement gaps (cracks) along each of these sections. This enabled an automated computation of crack width distributions and digital reproductions of the crack patterns from surface displacements occurring in a defined direction, which in this study was defined as the $x$-direction. However, there was still some surface displacement occurring perpendicular to the $x$-direction, as shown in Fig. 5b. The "real" crack width should be measured as the crack opening perpendicular to the direction of the crack. Nevertheless, the applied post-processing approach was considered to give a good approximation of the real crack widths for cracks with similar orientation.

One limitation of the 2D-DIC technique for crack measurements is that it is only capable of detecting cracks that emerge on the surface and not internal cracking, e.g. cracking due to plastic settlement around rebars [62,63], or cracking in the interface between the overlay and the restraining substrate [39]. In studies by Mauroux et al. [13] and Combrinck et al. [62] it was tried to overcome this limitation by studying internal shrinkage-induced cracks in depth through a transparent plate. However, this can only be done along the periphery of the specimen and is not representative of the whole internal interface. In this study, the restrained shrinkage specimens were epoxy impregnated after the test and cut into longitudinal slices, which enabled an analysis of the crack depth in the z-direction. This was only possible after ended test, so the approach did not enable observations on the crack depth propagation over time.
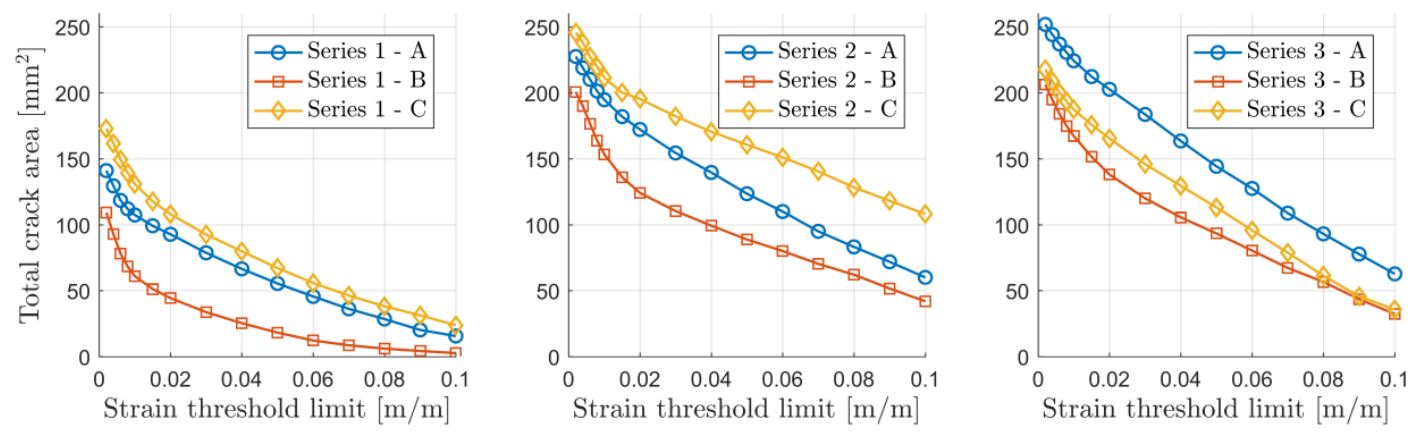

Fig. 14. Total crack area at $t=25$ h computed for strain threshold values varying from 0.002 to $0.1 \mathrm{~m} / \mathrm{m}$ for Series $1-3$, Specimens

\section{Conclusion}

The main objective of this study was to present a new test setup for studying the formation of in-plane surface cracking in restrained mortar overlays caused by plastic shrinkage. A digital image correlation (DIC) technique was used for crack detection and quantification. When applying the DIC technique for studying surface displacements, a high- 
contrast surface pattern is required, which is often applied using black and white spray paint. Since plastic shrinkage cracking is highly correlated with the rate of water evaporation from the fresh material, it is crucial that this spray paint does not lower the evaporation rate. A chalk-based spray paint was shown to have no influence on the evaporation rate, whereas acrylic-based paints caused a significant decrease in the evaporation rate by sealing the fresh mortar surface.

Quantification of the degree of surface cracking is highly relevant for a deeper understanding of the plastic shrinkage behaviour and this study showed that measurements based on a non-contact 2D-DIC technique allow the monitoring of in-plane strain and displacement fields over time. Based on the DIC data, crack parameters such as crack width, crack length, crack location and crack area could be automatically computed using a Matlab routine. Crack widths parallel to the length of the specimens were computed over a fine interpolated grid covering the entire specimen surface, which enabled a very detailed analysis of the crack width distribution. Moreover, digital reproductions of the surface crack patterns could be synthesized based on the DIC data. To verify the computed crack widths, the results were compared to manual measurements using optical microscope. From the microscope analysis, it was observed that the cracks are highly irregular in terms of crack width along the crack length and along the crack depth. Good correlation for measuring the widths of surface cracks was found between the DIC technique and measurements by optical microscope. Based on these results, it can be concluded that the DIC technique is a very promising method of performing automated measurement of surface displacements and cracking.

\section{References}

533 [1] J. Branston, S. Das, S.Y. Kenno, C. Taylor, Influence of basalt fibres on free and restrained plastic shrinkage,

\section{Acknowledgement}

The study is part of the project Circular Ocean, which is funded through the ERDF European Union Interreg VB Northern Periphery and Arctic (NPA) Programme 2014-2020 (Grant no. 21). Cem. Concr. Compos. 74 (2016) 182-190. doi:10.1016/j.cemconcomp.2016.10.004.

[2] W.P. Boshoff, R. Combrinck, Modelling the severity of plastic shrinkage cracking in concrete, Cem. Concr. Res. 48 (2013) 34-39. doi:10.1016/j.cemconres.2013.02.003.

[3] N. Banthia, C. Yan, Shrinkage cracking in polyolefin fiber-reinforced concrete, ACI Mater. J. 97.4 (2000) 432437. 
[4] P. Balaguru, Contribution of fibers to crack reduction of cement composites during the initial and final setting period, ACI Mater. J. 91.3 (1994) 280-288.

541 [5] N. Banthia, R. Gupta, Influence of polypropylene fiber geometry on plastic shrinkage cracking in concrete,

[6] ASTM C1579-13, Standard Test Method for Evaluating Plastic Shrinkage Cracking of Restrained Fiber

[7] M. Grzybowski, S.P. Shah, Shrinkage cracking of fiber reinforced concrete, ACI Mater. J. 87.2 (1990) 138-

[8] ASTM C1581, Standard Test Method for Determining Age at Cracking and Induced Tensile Stress

[10] N. Banthia, M. Azzabi, M. Pigeon, Restrained shrinkage cracking in fibre-reinforced cementitious composites, Mater. Struct. 26 (1993) 405-413.

[11] P.P. Kraai, A proposed test to determine the cracking potential due to drying shrinkage of concrete, Concr. Constr. 30.9 (1985) $775-778$.

[12] N. Banthia, R. Gupta, Test method for evaluation of plastic shrinkage cracking in fiber-reinforced cementitious materials, Exp. Tech. 31.6 (2007) 44-48. doi:10.1111/j.1747-1567.2007.00191.x.

[13] T. Mauroux, F. Benboudjema, P. Turcry, A. Aït-Mokhtar, O. Deves, Study of cracking due to drying in coating mortars by digital image correlation, Cem. Concr. Res. $42.7 \quad$ (2012) 1014-1023. doi:10.1016/j.cemconres.2012.04.002.

[14] A.E. Naaman, T. Wongtanakitcharoen, G. Hauser, Influence of different fibers on plastic shrinkage cracking of concrete, ACI Mater. J. 102.1 (2005) 49-58.

[15] P. Zhao, A.M. Zsaki, M.R. Nokken, Using digital image correlation to evaluate plastic shrinkage cracking in cement-based materials, Constr. Build. Mater. 182 (2018) 108-117. doi:10.1016/j.conbuildmat.2018.05.239.

[16] I.M.G. Bertelsen, L.M. Ottosen, G. Fischer, Quantitative analysis of the influence of synthetic fibres on plastic shrinkage cracking using digital image correlation, Constr. Build. Mater. 199 (2019) 124-137. doi:10.1001/archinte.168.13.1371. 
[17] K. Wang, S.P. Shah, P. Phuaksuk, Plastic shrinkage cracking in concrete materials - Influence of fly ash and fibers, ACI Mater. J. 98.6 (2001) 458-464.

[18] C. Wagner, B. Villmann, V. Slowik, V. Mechtcherine, Water permeability of cracked strain-hardening cementbased composites, Cem. Concr. Compos. 82 (2017) 234-241. doi:10.1016/j.cemconcomp.2017.06.003.

[19] N. Pešić, S. Živanović, R. Garcia, P. Papastergiou, Mechanical properties of concrete reinforced with recycled HDPE plastic fibres, Constr. Build. Mater. 115 (2016) 362-370. doi:10.1016/j.conbuildmat.2016.04.050.

[20] P. Soroushian, F. Mirza, A. Alhozaimy, Plastic shrinkage cracking of polypropylene fiber-reinforced concrete, ACI Mater. J. 92.5 (1995) 553-560.

[21] M.R. Jahanshahi, S.F. Masri, C.W. Padgett, G.S. Sukhatme, An innovative methodology for detection and quantification of cracks through incorporation of depth perception, Mach. Vis. Appl. 24 (2013) $227-241$. doi:10.1007/s00138-011-0394-0.

[22] G.M. Sadiqul Islam, S. Das Gupta, Evaluating plastic shrinkage and permeability of polypropylene fiber reinforced concrete, Int. J. Sustain. Built Environ. 5.2 (2016) 345-354. doi:10.1016/j.ijsbe.2016.05.007.

[23] N. Banthia, R. Gupta, Plastic shrinkage cracking in cementitious repairs and overlays, Mater. Struct. 42.5 (2009) 567-579. doi:10.1617/s11527-008-9403-9.

[24] C. Qi, J. Weiss, J. Olek, Characterization of plastic shrinkage cracking in fiber reinforced concrete using image analysis and a modified Weibull function, Mater. Struct. 36.6 (2003) 386-395. doi:10.1007/BF02481064.

[25] C. Liu, C.-S. Tang, B. Shi, W.-B. Suo, Automatic quantification of crack patterns by image processing, Comput. Geosci. 57 (2013) 77-80. doi:10.1016/j.cageo.2013.04.008.

[26] A. Mazzoli, S. Monosi, E.S. Plescia, Evaluation of the early-age-shrinkage of Fiber Reinforced Concrete (FRC) using image analysis methods, Constr. Build. Mater. $101.1 \quad$ (2015) 596-601. doi:10.1016/j.conbuildmat.2015.10.090.

[27] L. Ruiz-Ripoll, B.E. Barragán, S. Moro, J. Turmo, Digital imaging methodology for measuring early shrinkage cracking in concrete, Strain. 49 (2013) 267-275. doi:10.1111/str.12034.

[28] S. Ghourchian, M. Wyrzykowski, L. Baquerizo, P. Lura, Susceptibility of Portland cement and blended cement concretes to plastic shrinkage cracking, Cem. Concr. Compos. $85 \quad(2018) \quad 44-55$. doi:10.1016/j.cemconcomp.2017.10.002.

[29] M. Némoz-Gaillard, D. Nectoux, E. Dallies, D. Muller, Influence of AR glass fibers on the cracking of 
concrete: analysis at the very early age by digital image correlation, in: PRO 23 Int. RILEM Conf. Early Age Crack. Cem. Syst., 2002: pp. 237-244.

[30] P. Zhao, Master thesis. Digital Image Correlation to Evaluate Plastic Shrinkage Cracking in Cement-Based Materials, Concordia University, Montreal, Canada, 2016.

[31] A. Messan, P. Ienny, D. Nectoux, Free and restrained early-age shrinkage of mortar: Influence of glass fiber, cellulose ether and EVA (ethylene-vinyl acetate), Cem. Concr. Compos. 33.3 (2011) 402-410. doi:10.1016/j.cemconcomp.2010.10.019.

[32] E. Roziere, R. Cortas, A. Loukili, Tensile behaviour of early age concrete: New methods of investigation, Cem. Concr. Compos. 55 (2015) 153-161. doi:10.1016/j.cemconcomp.2014.07.024.

[33] E.D. Dzaye, E. Tsangouri, K. Spiessens, G. De Schutter, D.G. Aggelis, Digital image correlation (DIC) on fresh cement mortar to quantify settlement and shrinkage, Arch. Civ. Mech. Eng. 19 (2019) $205-214$. doi:10.1016/j.acme.2018.10.003.

[34] C.G. Berrocal, I. Löfgren, K. Lundgren, N. Görander, C. Halldén, Characterisation of bending cracks in R/FRC using image analysis, Cem. Concr. Res. 90 (2016) 104-116. doi:10.1016/j.cemconres.2016.09.016.

[35] B. Pan, K. Qian, H. Xie, A. Asundi, Two-dimensional digital image correlation for in-plane displacement and strain measurement: a review, Meas. Sci. Technol. 20.6 (2009) 062001. doi:10.1088/0957-0233/20/6/062001.

[36] D. Lecompte, A. Smits, S. Bossuyt, H. Sol, J. Vantomme, D. Van Hemelrijck, A.M. Habraken, Quality assessment of speckle patterns for digital image correlation, Opt. Lasers Eng. 44.11 (2006) 1132-1145. doi:10.1016/j.optlaseng.2005.10.004.

[37] M.A. Sutton, J.J. Orteu, H. Schreier, Image correlation for shape, motion and deformation measurements: basic concepts, theory and applications, Springer Science \& Business Media, 2009.

[38] A. Gheitasi, D.K. Harris, M. Hansen, An experimental-computational correlated study for describing the failure characteristics of concrete across two scale levels : Mixture and structural component, Exp. Mech. (2018) 1132. doi:10.1007/s11340-017-0319-6.

[39] W.P. Boshoff, F. Altmann, C.J. Adendorff, V. Mechtcherine, A new approach for modelling the ingress of deleterious materials in cracked strain hardening cement-based composites, Mater. Struct. 49.6 (2016) 22852295. doi:10.1617/s11527-015-0649-8.

[40] I. Maruyama, H. Sasano, M. Lin, Impact of aggregate properties on the development of shrinkage-induced 
cracking in concrete under restraint conditions, Cem. Concr. Res. 85 (2016) 82-101. doi:10.1016/j.cemconres.2016.04.004.

[41] I. Paegle, F. Minelli, G. Fischer, Cracking and load-deformation behavior of fiber reinforced concrete: Influence of testing method, Cem. Concr. Compos. 73 (2016) 147-163. doi:10.1016/j.cemconcomp.2016.06.012.

[42] F. Benboudjema, T. Mauroux, P. Turcry, A. Ait-Mokthar, O. Deves, Experimental Analysis of Drying Shrinkage Cracking in Coating Mortars by Digital Image Correlation, in: 2013. doi:10.1061/9780784413111.027.

[43] Y.L. Dong, B. Pan, A review of speckle pattern fabrication and assessment for digital image correlation, Exp. Mech. 57 (2017) 1161-1181. doi:10.1007/s11340-017-0283-1.

[44] P.J. Uno, Plastic shrinkage cracking and evaporation formulas, ACI Mater. J. 95.4 (1998) 365-375.

[45] E.D. Dzaye, G. De Schutter, D. Aggelis, Monitoring fresh cementitious material by digital image correlation ( DIC ), in: SynerCrete18, 2018: pp. 267-272.

[46] E.D. Dzaye, G. De Schutter, D. Aggelis, Application of digital image correlation to cement paste, in: Proceedings. Eighteenth Int. Conf. Exp. Mech., 2018. doi:10.3390/ICEM18-05332.

[47] S. Ghourchian, M. Wyrzykowski, L. Baquerizo, P. Lura, Performance of passive methods in plastic shrinkage cracking mitigation, Cem. Concr. Compos. 91 (2018) 148-155. doi:10.1016/j.cemconcomp.2018.05.008.

[48] E. Boghossian, L.D. Wegner, Use of flax fibres to reduce plastic shrinkage cracking in concrete, Cem. Concr. Compos. 30.10 (2008) 929-937. doi:10.1016/j.cemconcomp.2008.09.003.

[49] J.H.J. Kim, C.G. Park, S.W. Lee, S.W. Lee, J.P. Won, Effects of the geometry of recycled PET fiber reinforcement on shrinkage cracking of cement-based composites, Compos. Part B Eng. 39.3 (2008) 442-450. doi:10.1016/j.compositesb.2007.05.001.

[50] UNI/EN-1339, Concrete Paving Flags - Requirements and Test Methods, (2003).

[51] C.A. Juarez, G. Fajardo, S. Monroy, A. Duran-Herrera, P. Valdez, C. Magniont, Comparative study between natural and PVA fibers to reduce plastic shrinkage cracking in cement-based composite, Constr. Build. Mater. 91 (2015) 164-170. doi:10.1016/j.conbuildmat.2015.05.028.

[52] UNI/EN-12390-3, Testing Hardened Concrete - Part 3 : Compressive Strength of Test Specimens, (2012).

[53] V. Slowik, M. Schmidt, R. Fritzsch, Capillary pressure in fresh cement-based materials and identification of the air entry value, Cem. Concr. Compos. 30.7 (2008) 557-565. doi:10.1016/j.cemconcomp.2008.03.002. 
[54] ACI Committee 305.1-06, Specification for Hot Weather Concreting, (2007) 305.1-06.

[55] Ł. Skarzynski, J. Kozicki, J. Tejchman, Application of DIC technique to concrete - study on objectivity of measured surface displacements, Exp. Mech. (2013) 1545-1559. doi:10.1007/s11340-013-9781-y.

[56] W.P. Boshoff, C.J. Adendorff, Effect of sustained tensile loading on SHCC crack widths, Cem. Concr. Compos. 37 (2013) 119-125. doi:10.1016/j.cemconcomp.2012.11.009.

[57] F. Lagier, X. Jourdain, C. De Sa, F. Benboudjema, J.B. Colliat, Numerical strategies for prediction of drying cracks in heterogeneous materials: Comparison upon experimental results, Eng. Struct. 33.3 (2011) 920-931. doi:10.1016/j.engstruct.2010.12.013.

[58] V. Valle, S. Hedan, P. Cosenza, A.L. Fauchille, M. Berdjane, Digital image correlation development for the study of materials including multiple crossing cracks, Exp. Mech. 55.2 (2015) 379-391. doi:10.1007/s11340014-9948-1.

[59] R. Ranade, J. Zhang, J.P. Lynch, V.C. Li, Influence of micro-cracking on the composite resistivity of engineered cementitious composites, Cem. Concr. Res. 58 (2014) 1-12. doi:10.1016/j.cemconres.2014.01.002.

[60] N. Yousefieh, A. Joshaghani, E. Hajibandeh, M. Shekarchi, Influence of fibers on drying shrinkage in restrained concrete, Constr. Build. Mater. 148 (2017) 833-845. doi:10.1016/j.conbuildmat.2017.05.093.

[61] L. Ma, Y. Zhao, J. Gong, Restrained early-age shrinkage cracking properties of high-performance concrete containing fly ash and ground granulated blast-furnace slag, Constr. Build. Mater. 191 (2018) 1-12. doi:10.1016/j.conbuildmat.2018.09.154.

[62] R. Combrinck, L. Steyl, W.P. Boshoff, Interaction between settlement and shrinkage cracking in plastic concrete, Constr. Build. Mater. 185 (2018) 1-11. doi:10.1016/j.conbuildmat.2018.07.028.

[63] F. Sayahi, Plastic shrinkage cracking in concrete, Luleå University of Technology, 2016. doi:10.3929/ETHZ-B000249246. 